\title{
Lens-Photovoltaic Cell Coupling in a Holographic Solar Concentration System
}

\author{
Julia Marín-Sáez ${ }^{1}$, María Victoria Collados ${ }^{2}$, Daniel Chemisana ${ }^{1}$, Jesús Atencia ${ }^{2}$ \\ ${ }^{1}$ Applied Physics Section of the Environmental Science Department, University of Lleida, Lleida, Spain \\ e-mail:jmarin@macs.udl.cat \\ ${ }^{2}$ Tecnologías Ópticas Láser (TOL) \\ Instituto de Investigación en Ingeniería de Aragón (I3A) \\ Universidad de Zaragoza, Mariano Esquillor s/n, 50018, Zaragoza, Spain.
}

Tel. +34-976762707

\begin{abstract}
A solar concentration system formed by two holographic cylindrical lenses is proposed. It redirects part of the incident solar spectrum towards a PV cell, concentrating only the cell's most efficient wavelength range, while the rest is transmitted, not causing overheating. Simulations with one- and two-axes tracking are carried out.
\end{abstract}

\section{Introduction}

Solar concentration is a technique used in photovoltaics (PV) to reduce the PV cell surface that is needed to generate the same current intensity, to minimize the economical and environmental cost of the system. However, overheating due to the concentration of parts of the spectrum that will not be used by the cell, such as infrared, may cause a worsening of the cell performance.

Holographic Optical Elements (HOEs) are an outstanding alternative to conventional optical concentrating elements ${ }^{1}$, since they present an advantageous characteristic: chromatic selectivity (the incident wavelength affects the efficiency). The design of the HOE must take into account the solar spectrum as well as the spectral response of the PV cell, both plotted in Figure 1 (for a mono-crystalline Si cell). In this case, the wavelengths for which the HOE should be most efficient are around $800 \mathrm{~nm}$, to achieve a compromise between the two curves.

Holograms have angular selectivity as well, so their efficiency depends on the angle of incidence of the incoming rays. When it varies along one direction the efficiency decreases promptly (direction of high angular selectivity); whereas if it varies along the perpendicular direction, the efficiency decreases slowly (direction of low angular selectivity).

Tracking of the apparent solar movement in the sky is often carried out in two directions so that the incidence angle is kept the same. Holographic cylindrical lenses, which concentrate the diffracted beam on a line at a different position for each wavelength, enable tracking suppression in the direction of the daily movement, if it matches the direction of low angular selectivity ${ }^{2}$. That way only one-axis tracking is needed, simplifying the system.

A ray tracing algorithm ${ }^{3}$ based on Kogelnik's Coupled Wave Theory ${ }^{4}$ has been developed. It allows an independent analysis of each point of the HOE. The incident spectrum is the solar spectrum AM 1.5D from Figure 1, and Fresnel reflection losses $^{5}$ are taken into account.

\section{System description}

A concentrating system formed by two identical holographic cylindrical lenses with the design shown in Figure 2 is proposed. They direct incoming light towards a PV cell, that also receives the light coming from the space between them, covered with glass. The direction where tracking is not necessary is marked in the figure as well. When reconstructing with normal incidence and $800 \mathrm{~nm}$ wavelength, the efficiency of the HOEs is maximal.

\section{Results}

Simulations have been carried out to calculate the irradiance at the PV cell when tracking is carried out in two directions and in only one.

Figure 3 shows the irradiance on the cell coming from one of the holographic lenses (depicted with a blue line), the space between the lenses (orange line) and the complete system (yellow line), with normal incidence. Whereas the spectrum corresponding to the space between the lenses is similar to the solar spectrum (with lower values do to the reflection losses on the entrance and output surfaces), the spectrum corresponding to one of the lenses ranges between 600 and $880 \mathrm{~nm}$, approximately, and is enhanced around $800 \mathrm{~nm}$, as expected.

Revista "Jornada de Jóvenes Investigadores del I3A", vol. 5 (Actas de la VI Jornada de Jóvenes Investigadores del I3A - 2 de junio de 2017). ISSN 2341-4790. 
The total irradiance collected by the cell is 1594 $\mathrm{W} / \mathrm{m}^{2}$, which is higher than the incident solar irradiance, $1000 \mathrm{~W} / \mathrm{m}^{2}$. It may seem a low value, considering that two lenses contribute to the concentration; however, it needs to be taken into account that this spectrum corresponds mainly to the most sensitive wavelength range of the PV cell, as shown in Figure 3. The total short circuit current density obtained is $J_{S C}=812 \mathrm{~A} / \mathrm{m}^{2}, 1.83$ times what would be obtained without the concentration system but without excessively increasing its temperature.

If tracking is carried out in one direction only, similar current intensities can be expected for variations of the angle of incidence up to $20^{\circ}$.

\section{Conclusions}

A solar concentrator system formed by two holographic cylindrical lenses has been designed. Simulations have been carried out with a ray tracing algorithm to analyze its performance, with one-axis and two-axes tracking. Good lens-PV cell spectral response coupling provides higher irradiance and, therefore, current density values, without an excessive increase of the temperature on the cell.

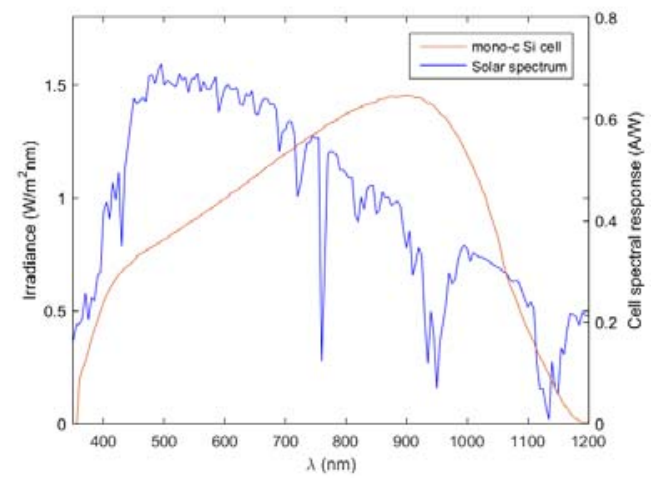

Figure 1: ASTM standard solar spectrum AM 1.5D normalized to $1000 \mathrm{~W} / \mathrm{m}^{2}$ over the spectral range 350 $1200 \mathbf{~ n m}$ (blue curve, left y-axis). Spectral response of a mono-crystalline Si cell (red curve, right y-axis).

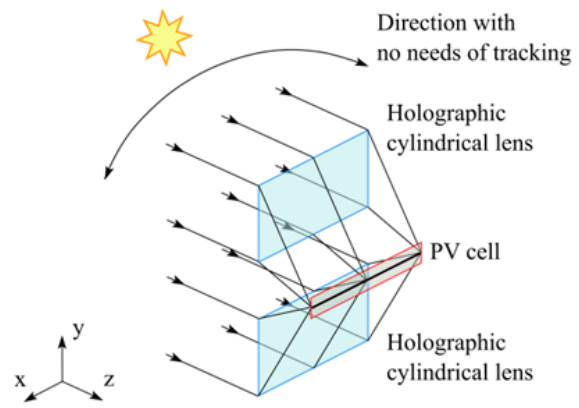

Figure 2: Scheme of the holographic concentrating system.

\section{REFERENCES}

[1] COllados, M. V., CHEMisANA, D. and ATENCIA, J. Holographic solar energy systems: The role of optical elements. Renew. Sustain. Energy Rev. 2016, 59, 130-140.

[2] BAÑARES-PALACIOS, P., ÁLVAREZ-ÁLVAREZ, S., MARÍN-SÁEZ, J., COLLADOS, M.-V., CHEMISANA, D. and ATENCIA, J. Broadband behavior of transmission volume holographic optical elements for solar concentration. Opt. Express. 2015, 23(11), A671-A681.

[3] MARÍN-SÁEZ, J., COLLADOS, M. V., ATENCIA, J. and CHEMISANA, D. Optical and Energetic Performance of Volume Holographic Optical Elements for Solar Energy Applications. Advances in Energy Research vol. 26. NOVA Science publishers 2017.

[4] KOGELNIK, H. Coupled wave theory for thick hologram gratings. Bell Syst. Tech. J. 1969, 48(9), 2909-2947.

[5] HECHT, E., Optics, Addison Wesley 1998.

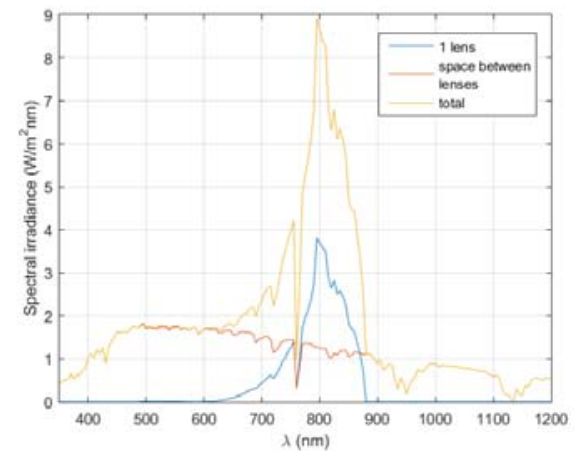

Figure 3: Spectral irradiance received by the PV cell emerging from one of the holographic lenses (blue curve), from the space between the two lenses (orange curve) and from the whole system (yellow curve). 